\title{
Antimicrobial Susceptibility among Urban Wastewater and Wild Shellfish Isolates of Non-01/Non-0139 Vibrio cholerae from La Rance Estuary (Brittany, France)
}

OPEN ACCESS

Edited by: Learn-Han Lee,

Monash University Malaysia, Malaysia

Reviewed by:

Iddya Karunasagar Nitte University, India

Marie-Cecile Ploy,

University of Limoges, France

*Correspondence:

Sandrine Baron sandrine.baron@anses.fr

Specialty section:

This article was submitted to

Food Microbiology,

a section of the journal

Frontiers in Microbiology

Received: 01 June 2017

Accepted: 11 August 2017 Published: 12 September 2017

Citation:

Baron S, Larvor E, Chevalier S, Jouy E, Kempf I, Granier SA and Lesne J (2017) Antimicrobial

Susceptibility among Urban Wastewater and Wild Shellfish Isolates of Non-01/Non-0139 Vibrio cholerae from La Rance Estuary (Brittany, France). Front. Microbiol. 8:1637. doi: 10.3389/fmicb.2017.01637

\author{
Sandrine Baron ${ }^{1,2 *}$, Emeline Larvor ${ }^{1,2}$, Séverine Chevalier ${ }^{2,3}$, Eric Jouy ${ }^{1,2}$, \\ Isabelle Kempf ${ }^{1,2}$, Sophie A. Granier ${ }^{4}$ and Jean Lesne ${ }^{2,3}$
}

${ }^{1}$ Mycoplasmology-Bacteriology Unit, Ploufragan-Plouzané Laboratory, French Agency for Food, Environmental and Occupational Health and Safety (Anses), Ploufragan, France, ${ }^{2}$ Bretagne-Loire University, Rennes, France, ${ }^{3}$ Ecole des Hautes Etudes en Santé Publique, Laboratoire d'Etude et de Recherche en Environnement et Santé, Institut de Recherche en Santé, Environnement et Travail, UMR 1085, Rennes, France, ${ }^{4}$ Laboratory for Food Safety, French Agency for Food, Environmental and Occupational Health and Safety (Anses), Paris-Est University, Maisons-Alfort, France

The early 2000s marked the end of the Golden age of the antibiotics and the beginning of the awareness on the potential threat to human health due to the dissemination of antimicrobial resistance. As a base-line study, we investigated the antimicrobial susceptibility of 99 strains of non-01/non-O139 Vibrio cholerae isolated from wastewater and shellfish in 2000/2001 within La Rance estuary (Brittany, France). All isolates were susceptible to amoxicillin-clavulanic acid, cefotaxime, imipenem, chloramphenicol, nalidixic acid, ciprofloxacin, norfloxacin, amikacin, gentamicin, tetracycline, doxycycline, trimethoprim-sulfamethoxazole, and erythromycin. The only resistances were to streptomycin, sulfonamides and ampicillin: $54.6 \%$ of the isolates had acquired resistance to at least one antimicrobial agent among them and only six isolates from cockles were multidrug resistant. On the basis of the distribution of a limited selection of resistance associated genes, our study shows that $V$. cholerae can constitute an environmental reservoir for these genes. However, none of our isolates harbored integron. This result casts doubt on the capacity of non-01/non-0139 V. cholerae to acquire resistance-associated genes in such context, and on its potential role of indicator of the dissemination of antimicrobial resistance in the aquatic environment.

Keywords: Vibrio cholerae non-01/non-0139, wastewater, wild shellfish, antimicrobial resistance, estuary

\section{INTRODUCTION}

The early 2000s marked the end of a 50 year time referred as the "Golden age of antibiotics" and the beginning of the awareness of the public health importance of the dissemination of antimicrobial resistance. Recent studies highlighted the important role of the aquatic environment in the dissemination of antimicrobial resistance (Baquero et al., 2008) and particularly wastewater which is considered as a hot spot for horizontal genes transfer (Bouki et al., 2013; Rizzo et al., 2013).

Vibrio cholerae is known to be an autochthonous inhabitant of riverine and estuarine aquatic environments and also a waterborne bacterial pathogen. The agent of cholera, a major public health threat for developing countries, belongs to serogroups $\mathrm{O} 1$ or $\mathrm{O} 139$ and produces the cholera toxin. 
The other serogroups are collectively referred as non-O1/non-O139 V. cholerae. Majority of strains isolated from the environment do not produce the cholera toxin and belong to non-O1/non-O139 serogroups.

In Europe, the increase of the frequency of infections due to non-O1/non-O139 $V$. cholerae in connection with the aquatic environment is reported by numerous authors (Dalsgaard et al., 2000; Ninin et al., 2000; Andersson and Ekdahl, 2006; Ottaviani et al., 2011; Hirk et al., 2016). This increase may be partially related to global warming. Due to the impact of climate change, a rise in the occurrence of $V$. vulnificus and $V$. cholerae is predicted for European waters (Baker-Austin et al., 2017).

Vibrio cholerae may act as an environmental reservoir for antibiotic resistance genes (Ceccarelli et al., 2016). It has been established that $V$. cholerae, irrespective of serogroup, has a plastic genome and a long history of successful association with plasmids (Coppo et al., 1995; Carraro et al., 2016). In other words, $V$. cholerae, due to its genetic characteristics, is possibly capable of acquiring and of exchanging genes through either integrons or integrative and conjugative elements (ICE) such as the SXT element (Waldor et al., 1996; Hochhut et al., 2001).

Within La Rance estuary, a survey on the presence of non-O1/non-O139 V. cholerae was performed during 2000/2001 in a field of wild shellfish-a point of exposure for humans-and upstream in the discharge of wastewaters from an agglomeration. This estuary opens into The English Channel and is located in Brittany (France). It is a typical environmental aquatic composite, characterized by high anthropogenic pressure. The water body is subject (i) to an artificial tide controlled by tidal power plant, which also causes important sedimentation in the upper part of the estuary, and (ii) to heavy inputs from human activity, mainly diffuse pollution and wastewater discharge from the treatment plant of the Dinan urban area (11,000 inhabitants). It is also an area of intensive recreational activity (sailing, fishing, bathing, collection of shellfish from the shore), and aquaculture (algae cultivation, oyster farming). The estuary is therefore simultaneously an environment receiving discharges from human activities, a potential reactor for genetic exchanges between bacteria subjected to antibiotic pressure and a source of diverse human exposures.

The aim of this study therefore was to investigate the antibiotic susceptibility of isolates of non-O1/non-O139 V. cholerae collected in 2000/2001 in cockles and in treated wastewater, in order to be used as base-line study of antimicrobial resistance.

\section{MATERIALS AND METHODS}

\section{Sampling Site and Study Period}

Two sites located in La Rance estuary (North Brittany, France) were sampled in 2000 and 2001. A wild shellfish harvesting area located in Mordreuc $\left(48^{\circ} 30^{\prime} 43 \mathrm{~N}, 1^{\circ} 58^{\prime} 37 \mathrm{~W}\right)$ on the shore was sampled seven times between June and October 2000 and twice in September 2001.

Treated wastewater was collected upstream at the outlet of the Dinan biological aerobic treatment plant (BTP) with trickling filters and activated sludge $\left(48^{\circ} 27^{\prime} 48 \mathrm{~N}, 02^{\circ} 1^{\prime} 40 \mathrm{~W}\right)$. Eleven samples were collected, one every two weeks between June and October 2000 and two more in 2001 (in August and in September). The two sampling sites are $8.5 \mathrm{~km}$ apart following the bed of the river $(4.8 \mathrm{~km}$ between the discharge of wastewater upstream and the lock on the river and $3.7 \mathrm{~km}$ between the lock and the wild cockle shellfish harvesting area downstream) (Figure 1).

\section{Environmental Data}

For each wastewater sample, salinity, $\mathrm{pH}$ and temperature were recorded in situ.

The enumeration of E. coli and intestinal Enterococci was carried out using the 96-wells microplate (BioRad, France) most probable number (MPN) methods ISO 9308-2 and ISO 7899-1, respectively. The detection of $E$. coli in the 96-wells microplate is based on the expression of $\beta$-D-glucuronidase enzyme, while $\beta$-glucosidase is the target for intestinal Enterococci.

\section{Sample Processing}

Harvested cockles and water samples were transported to the laboratory in coolers and examined within $3 \mathrm{~h}$ of collection.

Upon arrival, wild cockles (Cerastoderma edule) were scrubbed under running tap water and opened aseptically, using a sterile knife. $250 \mathrm{~g}$ of flesh plus intra-valve liquid were homogenized with a blender in Phosphate-Buffered Saline $(1 / 3$ $\mathrm{w} / \mathrm{w})$ for two times $30 \mathrm{~s}$. Volumes of $10 \mathrm{~mL}$ and $1 \mathrm{~mL}$ of homogenate of cockles, and also volumes of $1 \mathrm{~mL}$ of tenfold dilutions were mixed with Alkaline Peptone Saline Water (ASPW; composition for 1 liter: $10 \mathrm{~g}$ peptone, $20 \mathrm{~g} \mathrm{NaCl}$ and $5 \mathrm{~g}$ yeast extract; post-autoclave $\mathrm{pH}: 8.6 \pm 0.2$ ), in 100 and $10 \mathrm{~mL}$ volumes for the raw homogenate, and in $10 \mathrm{~mL}$ volumes for the tenfold dilutions.

Sample volumes of $1 \mathrm{~L}$ and $100 \mathrm{~mL}$ of treated wastewater were filtered (Diaphragm pump N035.3 AN.18 KNF Neuberger, Village-Neuf, France) successively with glass microfiber filters GF/D (grade D, $2.7 \mu \mathrm{m}$; Whatman, Maidstone, UK), glass microfiber filters $\mathrm{GF} / \mathrm{C}$ (grade C, $1.2 \mu \mathrm{m}$; Whatman, Maidstone, UK), $0.45 \mu \mathrm{m}$ cellulose ester membranes (Millipore, Watford, UK) and $0.22 \mu \mathrm{m}$ cellulose ester membranes (Millipore, Watford, UK). The various filter sizes guaranteed the isolation of both fixed-form and free-living bacteria. For volumes of $1 \mathrm{~L}$ and $100 \mathrm{~mL}$, the filters were placed in $250 \mathrm{~mL}$ of sterile ASPW. The volumes of $10 \mathrm{~mL}$ were incorporated directly in 100 $\mathrm{mL}$ of ASPW, and sample volumes of $1 \mathrm{~mL}$ to $0.001 \mathrm{~mL}$ were incorporated in $10 \mathrm{~mL}$ of ASPW.

\section{Isolation of $\boldsymbol{V}$. cholerae}

After incubation at $41 \pm 1^{\circ} \mathrm{C}$ for 16 to $18 \mathrm{~h}, 0.1 \mathrm{~mL}$ of tenfold dilutions of the enrichment were spread over TCBS Agar (Difco) (Muic, 1990) and incubated at $37^{\circ} \mathrm{C}$ for $36 \mathrm{~h}$. From each enrichment, up to 32 yellow colonies isolated on TCBS Agar were transferred with sterile toothpicks onto Nutrient Agar without $\mathrm{NaCl}\left(\mathrm{NA}_{0}\right.$, Difco) to test for growth at $37^{\circ} \mathrm{C}$, and then submitted for an oxidase test (Bactident oxidase strips, Merck, Darmstadt, Germany). Positive isolates were considered to be presumptive $V$. cholerae (Baron et al., 2007). Identification of presumptive $V$. cholerae was confirmed by PCR (Nandi et al., $2000)$. Confirmed isolates $(n=216)$ were maintained at $-80^{\circ} \mathrm{C}$ in 

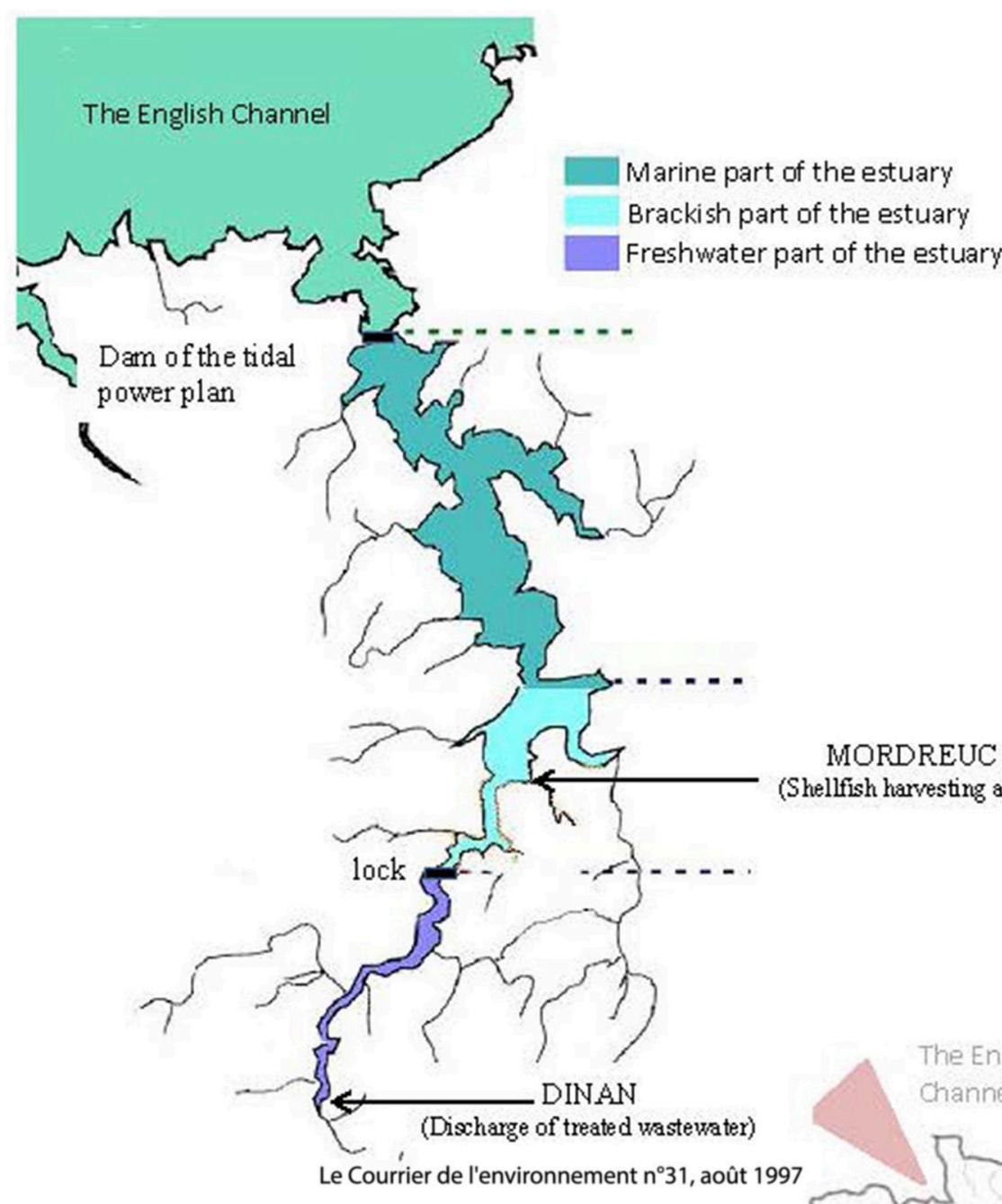

(Shellfish harvesting area)

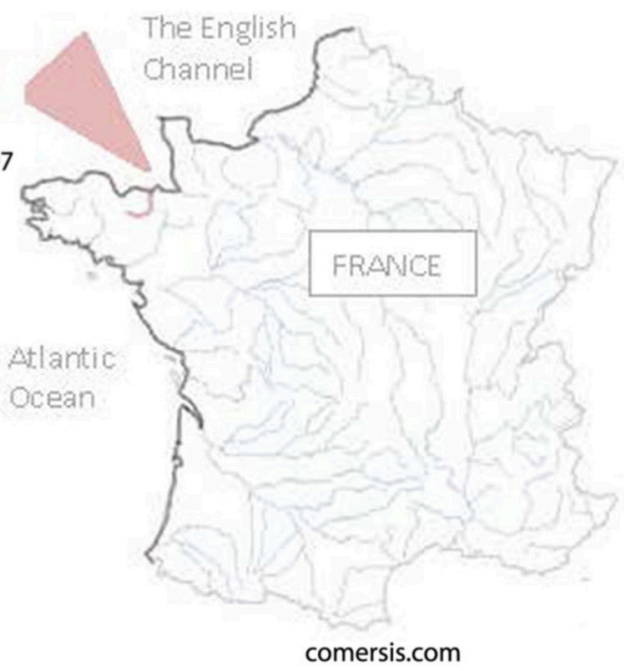

FIGURE 1 | Map of Rance estuary.

brain heart infusion broth (Bio-Rad) containing glycerol (10\%). Only one positive isolate per enrichment was conserved for further study (characterization and antibiotic susceptibility).

\section{Characterization of $\boldsymbol{V}$. cholerae}

Vibrio cholerae isolates were examined to determine whether they were members of the $\mathrm{O} 1$ serogroup via slide agglutination using a polyclonal antibody specific for the O1 surface antigen (Bio$\mathrm{Rad})$. A saline solution was used as a control to identify selfagglutinating isolates. The genes coding for the $\mathrm{O} 1$ and $\mathrm{O} 139$ surface antigens $(r f b)$ were assessed with PCR using O1-and O139-specific primers (Hoshino et al., 1998).

The virulence associated genes $t c p A, \operatorname{ctx} A$ and $h l y A$ were detected by PCR according to Rivera et al. (2001) and Fields 
et al. (1992) in the whole collection of confirmed V. cholerae nonO1/non-O139. Vibrio cholerae O1, Classical and Inaba obtained from Centre National de Référence des Vibrions et du Choléra, Institut Pasteur, Paris (CNRVC 940147), and Vibrio cholerae O1, El Tor and Inaba (ATCC 39315) obtained from the collection of the Pasteur Institute (Paris) were included as positive and negative controls where appropriate. All primer pairs, annealing temperatures, and amplicon sizes corresponding to target genes are listed in Table $\mathbf{1 .}$

\section{Enumeration of $\boldsymbol{V}$. cholerae}

For samples collected in 2000, enumeration of $V$. cholerae was done by the MPN method (5 tubes, 5 dilutions) based on the number of positive enrichments by serial fractions of volume for a sample (Beliaeff and Mary, 1993). The results were expressed per $100 \mathrm{~g}$ of flesh plus intra-valve liquid for cockles and per liter for wastewater. The number of dilutions and tested volumes were adapted according to the expected abundances. In 2001 no enumeration was done, the objective being only to collect isolates.

\section{Antimicrobial Susceptibility Testing}

The susceptibility of 99 isolates collected from cockles $(n=30$ in 2000 and $n=21$ in 2001) and from wastewater ( $n=31$ in 2000 and $n=17$ in 2001) was studied using the disk diffusion method) according to Clinical and Laboratory Standards Institute (CLSI) guidelines (CLSI, 2015). The 16 antimicrobial agents were chosen

TABLE 1 | The list of primer pairs, annealing temperatures, and amplicon sizes corresponding to target genes for PCR.

\begin{tabular}{|c|c|c|c|c|c|}
\hline Targeted gene & Primer name & Primer sequence $\left(5^{\prime}-3^{\prime}\right)$ & $\mathbf{T}^{\circ} \mathbf{C}^{\mathbf{a}}$ & Amplicon size (bp) & References \\
\hline \multirow[t]{2}{*}{ ermA } & ermA1 & TAACATCAGTACGGATATTG & 54 & 139 & Di Cesare et al., 2013 \\
\hline & ermA2 & AGTCTACACTTGGCTTAGG & & & \\
\hline \multirow[t]{2}{*}{ ermB } & ermB1 & CCGAACACTAGGGTTGCTC & & 200 & \\
\hline & ermB2 & ATCTGGAACATCTGTGGTATG & & & \\
\hline \multirow[t]{2}{*}{ mef } & mef1 & AGTATCATTAATCACTAGTGC & & 348 & \\
\hline & mef2 & TTCTTCTGGTACTAAAAGTGG & & & \\
\hline \multirow[t]{2}{*}{ sul1 } & sul1-1 & CGCACCGGAAACATCGCTGCAC & 65 & 162 & Pei et al., 2006 \\
\hline & sul1-2 & TGAAGTTCCGCCGCAAGGCTCG & & & \\
\hline \multirow[t]{2}{*}{ sul2 } & sul2-1 & TCCGGTGGAGGCCGGTATCTGG & 57.5 & 190 & \\
\hline & sul2-2 & CGGGAATGCCATCTGCCTTGAG & & & \\
\hline \multirow[t]{2}{*}{$0139 r f b$} & 0139-1 & AGCCTCTITATTACGGGTGG & 55 & 449 & Hoshino et al., 1998 \\
\hline & O139-2 & GTCAAACCCGATCGTAAAGG & & & \\
\hline \multirow[t]{2}{*}{$\mathrm{O} 1 \mathrm{rfb}$} & $01-1$ & GTICACTGAACAGATGGG & & 192 & \\
\hline & $01-2$ & GGTCATCTGTAAGTACAAC & & & \\
\hline \multirow[t]{2}{*}{$c t \times A$} & ctx Ats & CTCAGACGGGATITGTTAGGCACG & 64 & 301 & Nandi et al., 2000 \\
\hline & $\operatorname{ctx} A$ & TCTATCTCTGTAGCCCCTATTACG & & & \\
\hline \multirow[t]{2}{*}{ ompW } & ompW ts & CACCAAGAAGGTGACTITATTGTG & & 588 & \\
\hline & ompW ta & GAACTTATAACCACCCGCG & & & \\
\hline \multirow[t]{2}{*}{ strA } & strA-F & GAGAGCGTGACCGCCTCATT & 57 & 862 & Popowska et al., 2012 \\
\hline & strA-R & TCTGCTTCATCTGGCGCTGC & & & \\
\hline \multirow[t]{2}{*}{ strB } & strB-F & GCTCGGTCGTGAGAACAATC & 54 & 859 & \\
\hline & strB-R & AGAATGCGTCCGCCATCTGT & & & \\
\hline \multirow[t]{2}{*}{$\operatorname{ct} x A$} & $94 \mathrm{~F}$ & AGAATGCGTAAGCCATCTGT & 60 & 564 & Fields et al., 1992 \\
\hline & $614 \mathrm{R}$ & GAATGCGTAAGCCATCTGTIT & & & \\
\hline \multirow[t]{2}{*}{ tcpA Classical } & $72 F$ & TCTGCTTCATCTGGCGCTGC & 60 & 620 & Rivera et al., 2001 \\
\hline & $647 \mathrm{R}$ & TCTGCTTCATCTGGCGCTGC & & & \\
\hline \multirow[t]{2}{*}{ tcpA El Tor } & $72 \mathrm{~F}$ & TCTGCTTCATCTGGCGCTGC & & 451 & \\
\hline & $477 \mathrm{R}$ & TAACTGCTTCATCTGGCGCTGC & & & \\
\hline \multirow[t]{2}{*}{ hlyA Classical } & $744 \mathrm{~F}$ & CACAAGGTGACTITATTGTG & & 727 & \\
\hline & 1184R & CACCAAGAAGGTGACTITA & & & \\
\hline \multirow[t]{2}{*}{ hlyA El Tor } & $489 \mathrm{~F}$ & TTGTTACCCTITAATTGGCCC & & $738 / 727$ & \\
\hline & 1184R & CACCAAGAAGGTGACTाA & & & \\
\hline
\end{tabular}

${ }^{a}$ Annealing temperature. 
TABLE 2 | Phenotypic and genotypic profile of susceptibility in the 99 isolates of non-01/non-0139 V. cholerae.

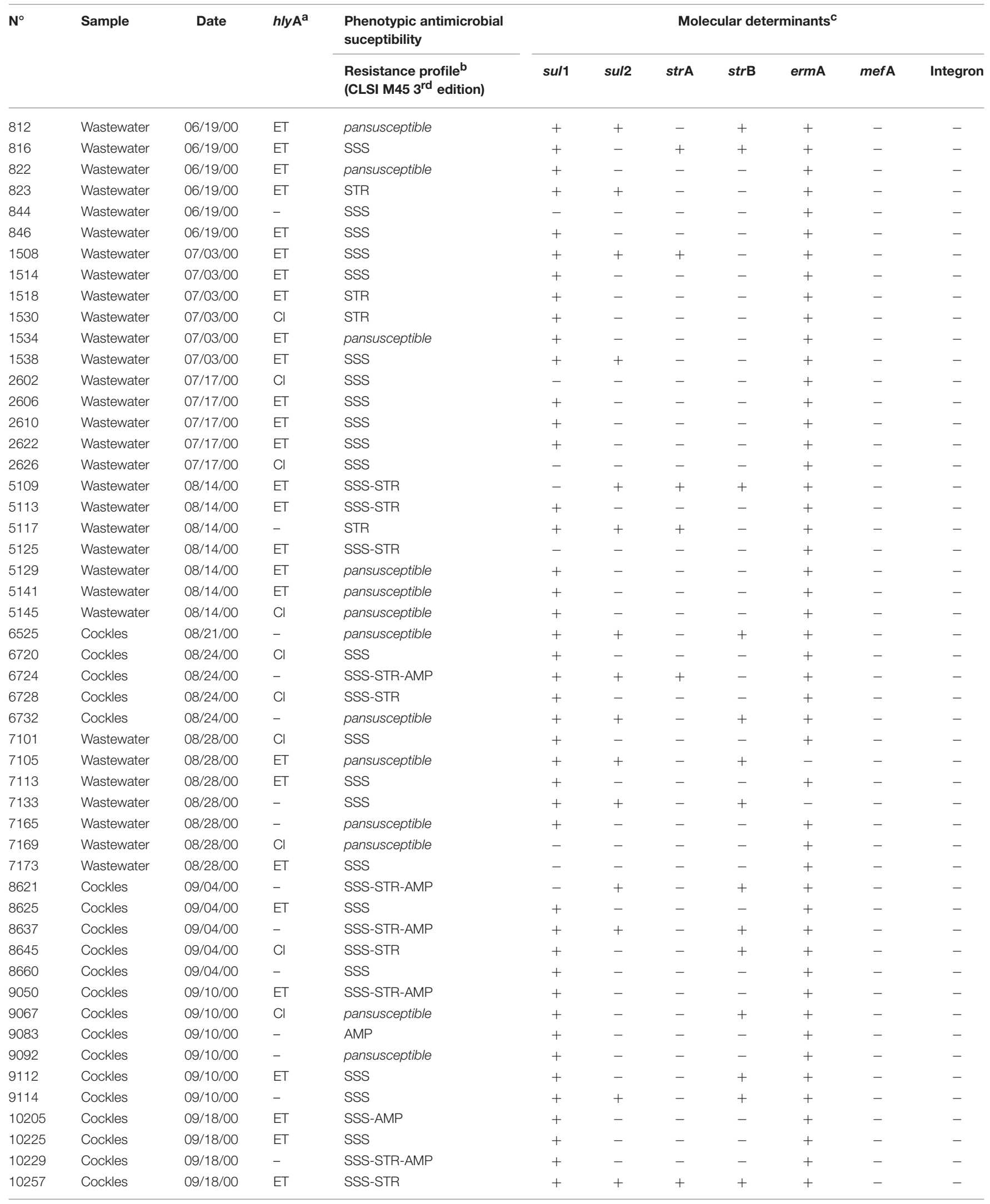


TABLE 2 | Continued

\begin{tabular}{|c|c|c|c|c|c|c|c|c|c|c|c|}
\hline \multirow[t]{2}{*}{$\mathbf{N}^{\circ}$} & \multirow[t]{2}{*}{ Sample } & \multirow[t]{2}{*}{ Date } & \multirow[t]{2}{*}{$h l y A^{a}$} & \multirow{2}{*}{$\begin{array}{l}\text { Phenotypic antimicrobial } \\
\text { suceptibility } \\
\begin{array}{l}\text { Resistance profile } \\
\text { (CLSI M45 } 3^{\text {rd }} \text { edition) }\end{array}\end{array}$} & \multicolumn{7}{|c|}{ Molecular determinants ${ }^{c}$} \\
\hline & & & & & sul1 & sul2 & strA & strB & ermA & mefA & Integron \\
\hline 10285 & Cockles & 09/18/00 & - & SSS & + & - & - & - & + & - & - \\
\hline 11013 & Cockles & 09/24/00 & ET & SSS-STR-AMP & - & - & - & - & + & - & - \\
\hline 11017 & Cockles & 09/24/00 & - & SSS & - & - & - & - & + & - & - \\
\hline 11037 & Cockles & $09 / 24 / 00$ & ET & SSS & + & - & - & - & + & - & - \\
\hline 11045 & Cockles & 09/24/00 & - & SSS & + & - & - & - & + & - & - \\
\hline 11053 & Cockles & 09/24/00 & $\mathrm{Cl}$ & SSS & + & - & - & - & + & - & - \\
\hline 11057 & Cockles & 09/24/00 & ET & STR & + & - & - & - & + & - & - \\
\hline 11063 & Cockles & 09/24/00 & - & pansusceptible & + & - & - & - & + & - & - \\
\hline 11109 & Cockles & $09 / 24 / 00$ & - & SSS-AMP & + & + & - & + & + & - & - \\
\hline 21855 & Wastewater & 08/06/01 & - & STR & + & - & - & - & + & - & - \\
\hline 21856 & Wastewater & 08/06/01 & ET & pansusceptible & + & + & - & - & + & + & - \\
\hline 21857 & Wastewater & 08/06/01 & - & pansusceptible & + & + & - & - & + & - & - \\
\hline 21858 & Wastewater & 08/06/01 & - & pansusceptible & + & + & - & - & + & - & - \\
\hline 21859 & Wastewater & 08/06/01 & - & pansusceptible & + & - & - & - & + & - & - \\
\hline 21860 & Wastewater & 08/06/01 & - & pansusceptible & + & + & - & - & + & - & - \\
\hline 21861 & Wastewater & 09/18/01 & - & STR & + & + & - & - & + & + & - \\
\hline 21863 & Wastewater & 08/06/01 & - & pansusceptible & + & + & - & - & + & + & - \\
\hline 21864 & Wastewater & 08/06/01 & ET & SSS & + & - & - & - & + & - & - \\
\hline 21865 & Wastewater & 08/06/01 & $\mathrm{Cl}$ & pansusceptible & + & + & - & - & + & + & - \\
\hline 22410 & Wastewater & 08/20/01 & - & pansusceptible & + & + & - & - & + & - & - \\
\hline 28207 & Cockles & 09/18/01 & - & pansusceptible & + & + & - & - & + & - & - \\
\hline 28208 & Cockles & 09/18/01 & - & pansusceptible & + & + & - & - & + & + & - \\
\hline 28209 & Cockles & 09/18/01 & ET & pansusceptible & + & + & - & - & + & - & - \\
\hline 28210 & Cockles & 09/18/01 & - & pansusceptible & + & + & - & - & + & + & - \\
\hline 28211 & Cockles & 09/18/01 & $\mathrm{Cl}$ & STR & + & + & - & - & + & + & - \\
\hline 28219 & Cockles & 09/18/01 & ET & pansusceptible & + & + & - & - & + & - & - \\
\hline 28220 & Cockles & 09/18/01 & $\mathrm{ET}$ & pansusceptible & + & + & - & - & + & - & - \\
\hline 28222 & Cockles & 09/18/01 & - & pansusceptible & - & + & - & - & + & - & - \\
\hline 28223 & Cockles & 09/18/01 & - & pansusceptible & + & + & - & - & + & - & - \\
\hline 28224 & Cockles & 09/18/01 & $\mathrm{Cl}$ & STR & - & + & - & - & + & + & - \\
\hline 28229 & Cockles & 09/18/01 & - & pansusceptible & + & + & - & - & + & - & - \\
\hline 28237 & Cockles & 09/18/01 & $\mathrm{Cl}$ & pansusceptible & + & + & - & - & + & + & - \\
\hline 28238 & Cockles & 09/18/01 & $\mathrm{Cl}$ & pansusceptible & + & + & - & - & + & + & - \\
\hline 28242 & Cockles & 09/18/01 & - & pansusceptible & + & + & - & - & + & - & - \\
\hline 28253 & Cockles & 09/18/01 & $\mathrm{Cl}$ & pansusceptible & + & + & - & - & + & - & - \\
\hline 28254 & Cockles & 09/18/01 & $\mathrm{Cl}$ & pansusceptible & + & + & - & - & + & - & - \\
\hline
\end{tabular}

${ }^{a} E T$, hemolysin El Tor; Cl, hemolysin Classical; -, no hemolysin detected.

${ }^{b}$ Resistance profiles were defined using with CLSI breakpoint when available in other cases referred to Table 1 in Supplementary Material.

${ }^{c}+$, gene or integron was detected by PCR; -, gene or integron was not detected by PCR.

Pansusceptible, profile susceptible to all the tested antimicrobial agents.

SSS, sulfonamide; STR, streptomycin; AMP, ampicillin. 
in order to represent the main antimicrobial families used in France: ampicillin, amoxicillin-clavulanic acid, cefotaxime, imipenem, chloramphenicol, nalidixic acid, ciprofloxacin, norfloxacin, amikacin, gentamicin, streptomycin, tetracycline, doxycycline, sulfonamides, trimethoprim-sulfamethoxazole association, and erythromycin (Table 1 in Supplementary Material). The CLSI interpretative criteria for disk diffusion susceptibility testing of Vibrio spp. (CLSI, 2015) published in the M45 $3^{\text {rd }}$ edition were used for ampicillin, amoxicillin-clavulanic acid, cefotaxime, imipenem, chloramphenicol, ciprofloxacin, amikacin, gentamicin, tetracycline, sulfonamides, trimethoprimsulfamethoxazole association (Table 2). For nalidixic acid, norfloxacin, amikacin and streptomycin, the interpretative criteria for Enterobacteriaceae were used (CLSI, 2016) (Table 1 in Supplementary Material). No criterion was available for erythromycin or doxycycline; therefore, the distribution of the inhibition diameters was recorded and interpretation was based on obtained distribution plots. The separation between wild-type (microorganisms without acquired resistance mechanisms) and non-wild-type populations (microorganisms with acquired resistance mechanisms) was determined by visual inspection of the diameter distribution (Hombach et al., 2014). The intermediate results were considered as resistant for this study. Wild-type populations were considered as susceptible populations and non-wild-type as resistant populations.

\section{Antibiotic Resistance Associated Genes}

Screening for resistance-associated genes in our collection of isolates was done particularly to provide information on the reservoir of resistance genes in the autochthonous aquatic nonO1/non-O139 V. cholerae populations under study. As, in the early 2000s CTX-M enzymes have become the most prevalent extended-spectrum $\beta$-lactamases in Europe (Cantón and Coque, 2006), the bla $a_{\text {CTX-M }}$ was detected using PCR (Woodford et al., 2005). Genes associated with resistance to streptomycin (strA and $\operatorname{str} B$ ), to sulfonamides (sull and sul2)-which may be associated with the presence of $V$. cholerae SXT elementand to erythromycin (ermA, ermB and mef) were detected by PCR (Pei et al., 2006; Popowska et al., 2012; Di Cesare et al., 2013). Class 1, 2, and 3 integrons were screened using qPCR (Barraud et al., 2010). All primer pairs, annealing temperatures and amplicon sizes corresponding to target genes are listed in Table 1.

\section{Statistical Analysis}

To compare the characteristics of the isolates collected from cockles and wastewater the chi-squared test, and Pearson's chisquared test whenever needed, was used.

\section{RESULTS}

\section{Characterization and Enumeration of Vibrio cholerae}

None of the 216 isolates (cockles: 116, wastewater: 100) characterized for the MPN estimation-one isolate by positive enrichment broth-belonged to the O1 or the O139 serogroup (No agglutination was observed; absence of the $r f b$ sequence gene), and carried neither the ctxA gene, nor the El Tor or Classical variants of the tcpA gene. All $V$. cholerae isolates were therefore non toxigenic.

The frequency of the hemolysin gene variants El Tor or Classical was $52.3 \%$ (113 strains), without any difference between wastewater and cockle isolates (59.0 vs. $46.5 \%)$. The El Tor variant was detected in 66 isolates (30.5\%) and the Classical variant in 47 isolates $(21.8 \%)$.

In 2000, $V$. cholerae densities were recorded in cockles and in treated wastewater. In cockles, between June and September, concentrations of $V$. cholerae ranged from 2.5 to $230 \mathrm{MPN} / 100 \mathrm{~g}$ of flesh plus intra-valve liquid. The highest density was observed in September and $V$. cholerae was detected in all seven samples (Table 3). At the outlet of the biological aerobic treatment plan, $V$. cholerae was detected in $75 \%$ of the samples (9/12), and densities ranged from 0.075 MPN/L to 78.2 MPN/L (Figure 2). Abundance of $V$. cholerae was below the detection limit of the method once in September (09/25/2000-detection limit: 0.198 MPN/L) and twice in October (10/09/2000 and 10/23/2000detection limit: $0.181 \mathrm{MPN} / \mathrm{L})$. The highest densities were observed in August. The geographic mean is $0.6 \log _{10}(\mathrm{MPN} / \mathrm{L})$. The temperature followed the seasonal variation and ranged from $22.2^{\circ} \mathrm{C}$ in August to $16^{\circ} \mathrm{C}$ in October (Figure 2). The $\mathrm{pH}$ ranged from 6.31 to 7.51 with an average of $7.40 \pm 0.43$. The salinity ranged from 0.2 to $0.9 \%$. The densities of E. coli and intestinal Enterococci were relatively stable during the sampling period with geometric mean value of $4.9 \times 10^{5} \pm 0.5 \log _{10}(\mathrm{MPN} / 100 \mathrm{~mL})$ and $4.5 \pm 0.6 \log _{10}(\mathrm{MPN} / 100 \mathrm{~mL})$ respectively. Means densities per liter of $E$. coli were $5.3 \log _{10}$ unit higher than $V$. cholerae ones and intestinal Enterococci were $4.8 \log _{10}$ unit higher than $V$. cholerae densities (Figure 2).

In 2001, sampling dates were chosen in August and September to optimize the collection of isolates from cockles and wastewater.

\section{Antimicrobial Susceptibility}

All the 99 isolates studied were susceptible to the 11 following antimicrobial agents: amoxicillin-clavulanic acid, cefotaxime, imipenem, chloramphenicol, nalidixic acid, ciprofloxacin, norfloxacin, amikacin, gentamicin, tetracycline, trimethoprim-sulfamethoxazole association (Table 2).

For doxycycline and erythromycin, no breakpoint were available, based on the distribution of the diameter of inhibition

TABLE 3 | Densities of $V$. cholerae in cockle samples (MPN per $100 \mathrm{~g}$ of flesh plus intra-valve liquid) according to sampling dates.

\begin{tabular}{|c|c|c|c|c|c|c|c|}
\hline Sampling dates (month/day) & $08 / 24 / 2000$ & $09 / 04 / 2000$ & 09/17/2000 & $09 / 18 / 2000$ & $09 / 24 / 2000$ & $10 / 02 / 2000$ & $10 / 16 / 2000$ \\
\hline MPN & $3.8 \times 10^{1}$ & $2.3 \times 10^{2}$ & $1.0 \times 10^{2}$ & $3.4 \times 10^{2}$ & $8.0 \times 10^{1}$ & $2.5 \times 10^{0}$ & $1.5 \times 10^{2}$ \\
\hline
\end{tabular}




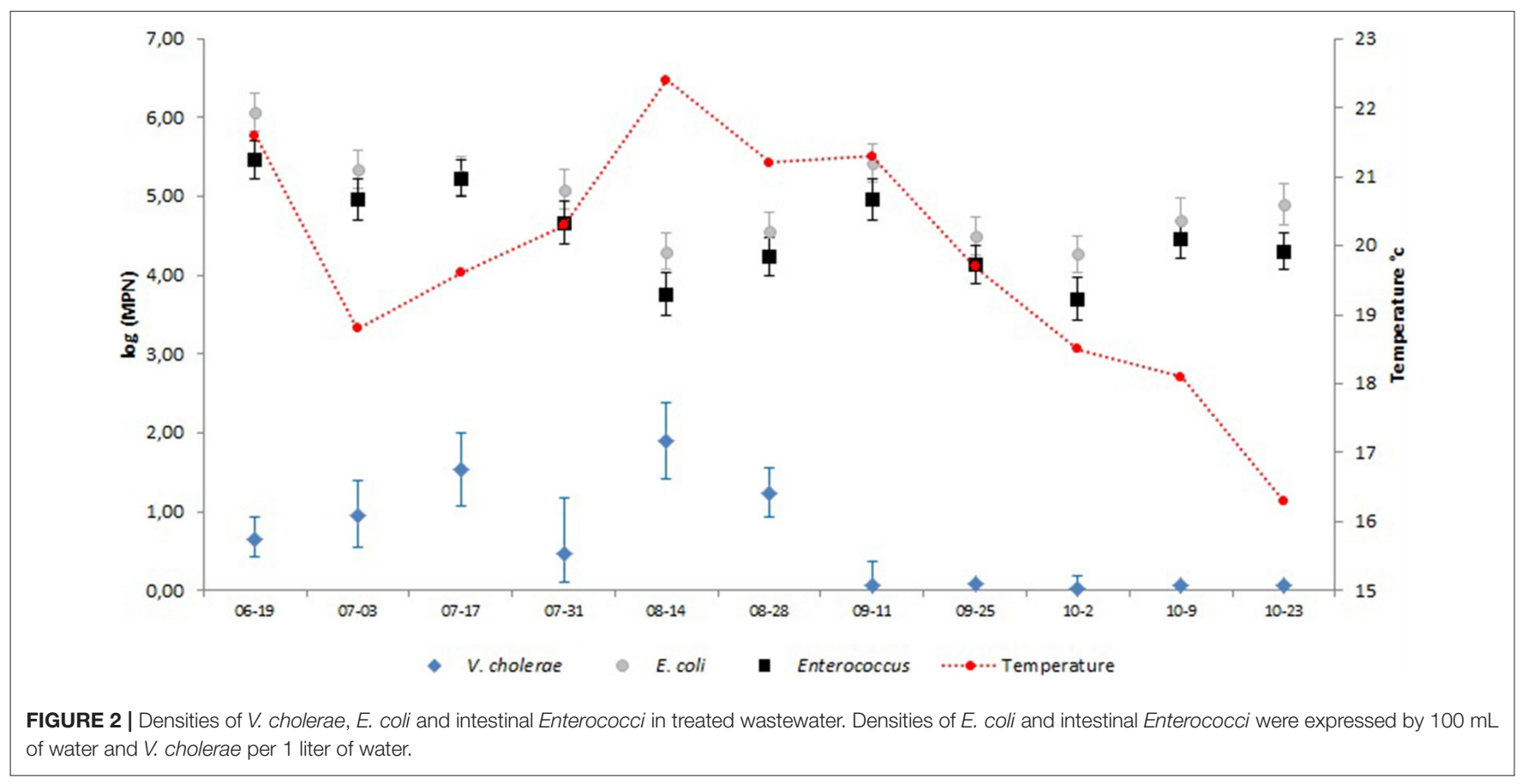

FIGURE 2 | Densities of $V$. cholerae, E. coli and intestinal Enterococci in treated wastewater. Densities of E. coli and intestinal Enterococci were expressed by $100 \mathrm{~mL}$ of water and $V$. cholerae per 1 liter of water.

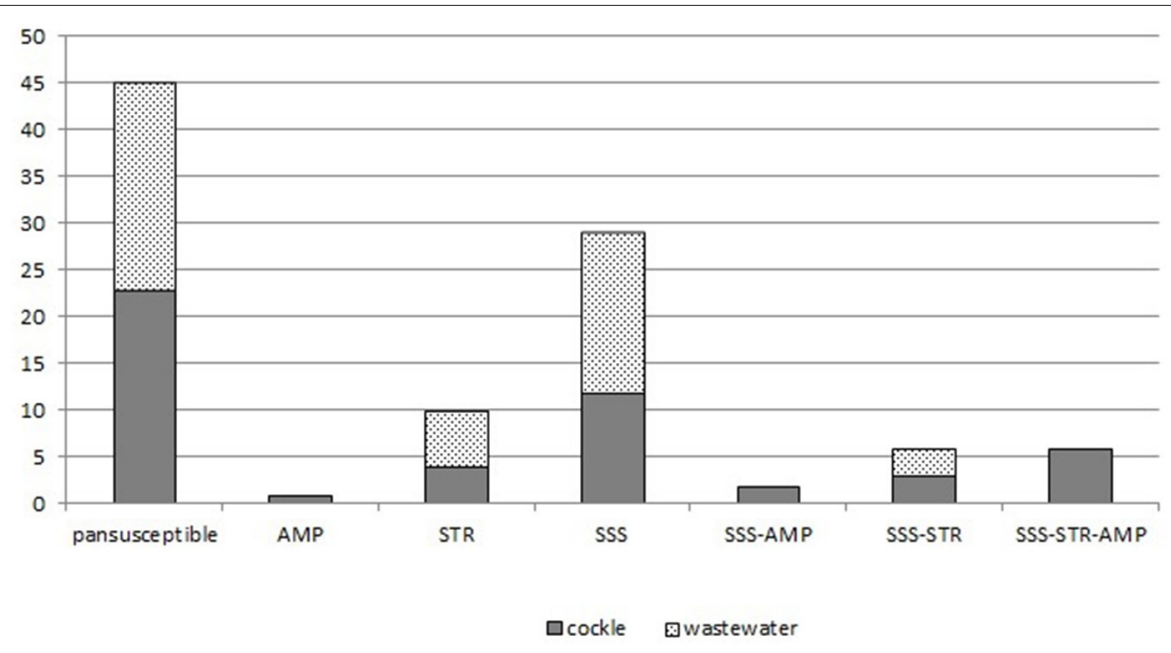

FIGURE 3 | Distribution of resistance profiles among the 99 isolates of non-01/non-0139 Vibrio cholerae.

(Figures 4A,B), only one population could be observed. All the strains were considered as susceptible (Baron et al., 2016).

Among the 54 isolates (54.6\%) that were resistant to at least one antimicrobial agent, 28 were collected in cockles and 26 in wastewater. The most frequent resistance was to sulfonamides (44 isolates), followed by streptomycin (22 isolates) and ampicillin (9 isolates). No significant difference was observed for the frequency of resistance to either sulfonamides or streptomycin between the isolates from cockles and those from wastewater. The nine isolates resistant to ampicillin were collected from cockles in 2000.

The most frequent resistance profile was susceptibility to the 16 antimicrobial agents tested $(n=45)$, then resistance to sulfonamides only $(n=29)$, followed by resistance to streptomycin only $(n=10)$. Six multi-drug resistant isolates were detected in cockles in 2000; none in wastewater. They were resistant to sulfonamides, ampicillin and streptomycin (Figure 3).

No difference was observed in the frequency of associated resistance genes between cockles and wastewater. Among the 99 isolates, neither the erm B nor the bla $a_{\mathrm{CTX}-\mathrm{M}}$ gene was detected. The most frequent gene was ermA $(n=97)$; sul1 and sul2 were detected in 86 and 49 isolates respectively (Table 4). None of the three classes of integron were detected in the $99 \mathrm{~V}$. cholerae strains (Table 2). 

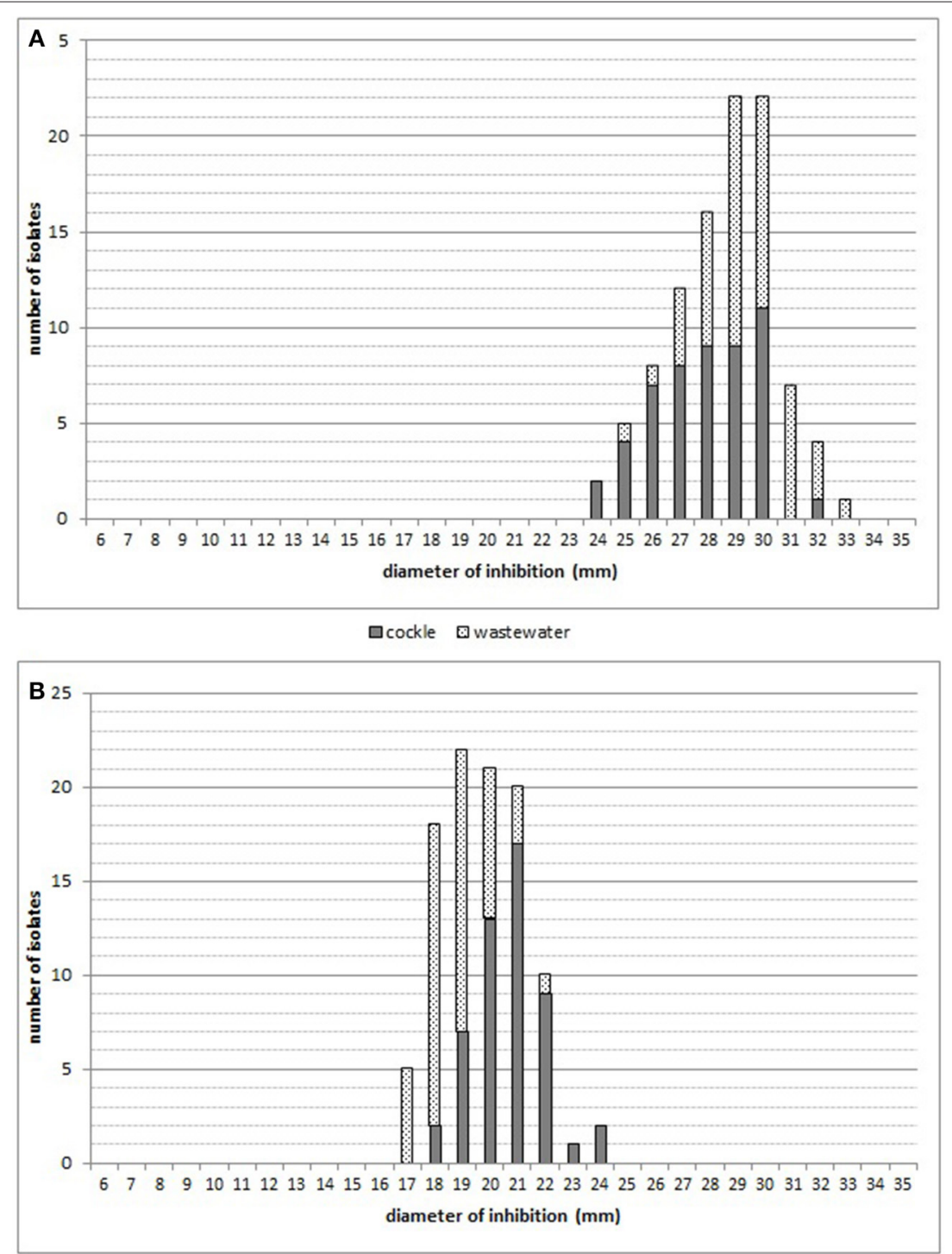

FIGURE 4 | Distribution of diffusion zone diameters: (A) doxycycline (30 $\mu \mathrm{g})$; (B) erythromycin (15 $\mu \mathrm{g})$.

Among the 45 isolates harboring sull and sul2, 10 were resistant to sulfonamides and 35 were susceptible. Similarly, for the isolates harboring str $\mathrm{A}$ and $\operatorname{str} \mathrm{B}$, two were resistant and four were susceptible to streptomycin. All the isolates harbored at least one of the eight targeted genes and $52.3 \%$ of the isolates harbored at least three genes. Only two isolates harbored simultaneously sul2, strA and strB (Table 4).

\section{DISCUSSION}

The objective of this baseline study was to characterize the susceptibility to antibiotics of non-toxigenic $V$. cholerae collected in 2000/2001 in a cholera-free area, at two points of interface between the aquatic environment and the human populationa discharge of urban wastewater and shellfish harvested from the shore downstream.

\section{Abundance of Vibrio cholerae}

The presence of $V$. cholerae in treated wastewater had never been described in France. Non-O1/non-O139 V. cholerae was detected in $75 \%$ of the wastewater samples at the outlet of the treatment plant of the city of Dinan. An investigation from our team conducted at the same time in stabilization ponds at SaintHelen, a village in the watershed of La Rance estuary, confirmed the persistent presence of $V$. cholerae in wastewater at another location (data not shown). To our knowledge, it can only be compared in Europe to the results of an Italian study: 19 strains were isolated from 69 samples of wastewater at the inlet and the outlet of a treatment plant (Gatti et al., 1997).

The levels of abundance of non-O1/non-O139 V. cholerae observed in the treated wastewater from Dinan (0.075 MPN/L to $\left.78 \times 10^{1} \mathrm{MPN} / \mathrm{L}\right)$ were much lower than those calculated with a comparable method of analysis, outside the context 
TABLE 4 | Distribution of resistance-associated genes among the 99 isolates of non-O1/non-0139 Vibrio cholerae.

\begin{tabular}{lccc}
\hline & Cockle & Wastewater & Total \\
\hline ermA & 2 & 7 & 9 \\
sul1 ermA & 17 & 20 & 37 \\
sul2 ermA & 1 & 9 & 1 \\
sul1 sul2 ermA & 11 & & 20 \\
sul1 strB ermA & 3 & 2 & 3 \\
sul1 sul2 strB & 1 & & 2 \\
sul2 ermA mef & 1 & 5 & 1 \\
sul2 strB ermA & 8 & 1 & 13 \\
sul1 sul2 ermA mef & 5 & 1 & 6 \\
sul1 sul2 strB ermA & & 1 & 1 \\
sul2 strA strB ermA & 1 & 2 & 3 \\
sul1 strA strB ermA & 1 & 48 & 1 \\
sul1 sul2 strA ermA & 51 & & 99 \\
sul1 sul2 strA strB ermA & & & \\
\hline Total & & & \\
\hline
\end{tabular}

of cholera, in Mediterranean Europe (Yugoslavia, wastewater discharge of a coastal town with 600,000 inhabitants, 1990: range from $2.0 \times 10^{2}$ to $2.1 \times 10^{5} \mathrm{MPN} / \mathrm{L}$ ) (Muic, 1990), or in North Africa (Marrakesh, at the outlet of experimental stabilization ponds, from January 1986 to December 1987: range from $<3 \times$ $10^{2}$ to $2.3 \times 10^{7} \mathrm{MPN} / \mathrm{L}$ (Lesne et al., 1991) and from October 1992 to September 1993: geometric mean in winter of $2.5 \times 10^{4}$ $\mathrm{MPN} / \mathrm{L}$, and geometric mean in summer of $1.7 \times 10^{6} \mathrm{MPN} / \mathrm{L}$ (Mezrioui and Oufdou, 1996). The only other recent study, to our knowledge, was done in South Africa from August 2011 to May 2012 (17 dates) but in the context of a cholera epidemic (Okoh et al., 2015). The levels of abundance of $V$. cholerae observed in four wastewater treatment plants discharging into rivers at four sampling points each (influent, effluent, upstream, downstream), i.e., in 272 samples of water, were still higher $\left(1.6 \times 10^{3} \mathrm{CFU} / \mathrm{L}\right.$ to $6.3 \times 10^{9} \mathrm{CFU} / \mathrm{L}$ ), but the method of analysis in that study is not comparable to ours. And an unspecified fraction of the counted population of $V$. cholerae is toxigenic in $40 \%$ of the samples, which is not the case in any of the other studies presented.

Sewage is oligohaline water, rich in organic matter, with a $\mathrm{pH}$ neutral to alkaline, characteristics which meet the requirements of $V$. cholerae for growth or survival. The abundance of $V$. cholerae also appeared higher under climates that include a hot season, which can be considered alongside the well-known favorable effect (direct or indirect) of water temperature on the growth of population of this bacterium in aquatic ecosystems. While it is well established that $V$. cholerae is autochthonous of the natural aquatic environment, its detection in sewage fed by a public water distribution network raises the question of its origin. At least two non-mutually-exclusive assumptions can be made: contribution of run-off waters and contribution of a possible healthy carriage in the gut of the human population (Morris, 1990). In any case, it seems that sewage establishes an ecosystem favorable to the installation and development of this species. We have no information about the presence of healthy carriers in the local human population, nor on local clinical cases of infection with non-O1/non-O139 V. cholerae. It is interesting to observe that intestinal carriage also exists in livestock (Rhodes et al., 1985) and that in our study, strains of non-O1/non-O139 $\mathrm{V}$. cholerae have also been isolated in the wastewater treatment plants of two neighboring slaughterhouses, one for pigs and the other for calves (Sandrine Baron, personal communication).

Between June and September 2000, V. cholerae was detected in all seven samples of cockles. The field of naturally-growing cockles was located in brackish water area (salinity between 0.5 and $30 \%$ ) in the upper estuary. Similar results were obtained in a field of mussels (Mytilus edulis) located in a zone where sea water (Northern Sea) mixes with brackish water (Baltic Sea), in The Sound (between Sweden and Denmark) during summer 2006: 100\% ( $n=19)$ of samples contained non-toxigenic $V$. cholerae (Collin and Rehnstam-Holm, 2011). In other salinity conditions, such as marine waters (salinity $\approx 33 \%$ o) or polyhaline waters (salinity between 18 and 30\%o), the frequencies of detection are much lower. In France, in summer 1999, only two strains of non-O1/non-O139 $\mathrm{V}$. cholerae were detected in two samples of mussels from the Channel, and two strains in one sample of mussels from the Atlantic Ocean (Hervio-Heath et al., 2002). Again in France, between 2006 and 2007, V. cholerae was not detected in mussels and clams of two lagoons which are open onto the Mediterranean Sea (Cantet et al., 2013). In Italy, during a national study from May to September 2006 on the Ligurian Adriatic and Tyrrhenian coasts, non-O1/non-O139 $V$. cholerae was present in only $7.8 \%(n=90)$ of mussel samples and never detected in the clam samples $(n=56)$ (Ottaviani et al., 2009). In 2011-2014, another study detected $V$ cholerae $c t x^{-} t c p^{-}$in only one sample of clams out of 112 collected (Passalacqua et al., 2016). In Germany, during a study of nonO1/non-O139 $V$. cholerae in mussels produced in the Wadden Sea, the frequencies of presence were $16 \%(n=46)$ in 2012 and $11 \%(n=71)$ in 2013 (Huehn et al., 2014). On the coast of the Atlantic Ocean, north of São-Paulo (Brazil), in mussels cultivated in sea water, less than $10 \%$ of samples collected between February 1989 and February 1990 were positive for non-O1/non-O139 $V$. cholerae. On the Northeast Atlantic Coast in Long Island Sound (USA) V. cholerae was detected in $8.8 \%(n=68)$ of oyster samples (Crassostea gigas) and in 3.3\% $(n=30)$ in clams. All these data show a higher frequency of detection of $V$. cholerae in brackish waters than in marine waters.

The following studies are the only ones that supply quantitative data of $V$. cholerae in shellfish. In Brazil, with a method similar to ours, the abundances are lower, varying between 7 and $2.3 \times 10^{1} \mathrm{MPN} / 100 \mathrm{~g}$ (Matté et al., 1994). In the USA, by using a PCR multiplex on enrichment broth, the abundances observed were between $3.6 \times 10^{1}$ and $3.0 \times 10^{3}$ MPN/100 g for oysters and $3.0 \times 10^{2}$ in the only sample of positive clams (Jones et al., 2014). This difference of method might explain the higher abundances.

\section{Characterization of the Isolates}

In France, the rare cases of cholera are imported (Geneste et al., 2000; Tarantola et al., 2007), thus the presence of the main virulence factors of cholera, $\operatorname{ctx} A$ and $t c p A$, is very improbable 
in the aquatic population of $V$. cholerae. The products of the ctxA gene are involved in interactions with the host that are responsible for pathological damage (Wassenaar and Gaastra, 2001). This gene encodes the cholera toxin A subunit. The $\operatorname{tcp} A$ gene is a colonization gene encoding the principal subunit of the toxin-coregulated pilus (type IV), which appears to facilitate the interaction between bacteria and the intestinal epithelium surface (Reidl and Klose, 2002). In our collection, the ctxA gene and the tcpA gene were never detected. Similarly, none of 11 isolates of non-O1/non-O139 $V$. cholerae collected from seafood samples (Italian coastal waters), harbored either the $c t x A$ or the tcpA genes (Ottaviani et al., 2009). Also in a collection of 395 strains of non-O1/non-O139 V. cholerae collected in Chesapeake Bay, Maryland (USA), in water, sediment and oyster samples during a Vibrio surveillance program (2009 to 2012), only four isolates harbored the $c t x A$ gene and none the $\operatorname{tcp} A$ gene (Ceccarelli et al., 2015).

Inversely, hlyA genes are frequently harbored by environmental isolates of non-O1/non-O139 $V$. cholerae. The hlyA gene encodes hemolysin, the production of which was originally used to differentiate Classical and El Tor V. cholerae O1 biotypes. Its role in virulence is not clearly established. However, it does not seem to be an essential factor for choleratype human pathogenesis, since the hemolytic function is absent in clinical isolates of the 6th pandemic (Classical biotype), and disappears gradually from isolates of the 7th (El Tor biotype) (Barrett and Blake, 1981). By contrast, in non-O1/non-O139 strains associated with cases of gastro-enteritis and diarrhea, but lacking virulence factors associated with cholera, hemolysin production might constitute an important virulence factor. In our study, $52.3 \%$ of the $V$. cholerae isolates harbored the hemolysin gene (variant El Tor or Classical without distinction) and no significant difference between cockles and wastewater was noticed. In comparison, all the 13 isolates of $V$. cholerae collected from seafood in Italy harbored hlyA (Ottaviani et al., 2009). Among 39 non-O1/non-O139 V. cholerae strains from Brazil, 94.9\% showed homology to El Tor hemolysin, 2.6\% were associated with Classical hemolysin, and $2.5 \%$ were negative for both genes (Rivera et al., 2001). Lastly, among the 395 environmental isolates collected by Ceccarelli et al. (2015), 83\% were hlyA positive, including the seven oyster isolates. In these studies, the El Tor variant was thus either the only variant detected or the most abundant. In our study, the El Tor variant was found in only $30.5 \%(n=66)$ of the isolates and the Classical variant in $21.8 \%(n=47)$. The Classical biotype has an $11 \mathrm{bp}$ deletion within the $h l y A$ coding region, compared to the El Tor biotype, resulting in a truncated and non-hemolytic hly $A$ product which may have another, as yet unknown, function (Rader and Murphy, 1988; Alam et al., 1997). It suggests that a part of our isolates would not be capable of producing a functional hemolysin, or at best a less active one. It could be verified by carrying out in vitro tests following the example of those performed by Ottaviani et al. (2009).

Other genes, such as rtxA, chxA, T6SS, hapA, nanH, etc... are suspected of being involved in the virulence of toxigenic $V$. cholerae; but this does not mean that their role is well defined. Their detection in environmental isolates helps to better characterize these isolates and to estimate the genetic reservoir associated with virulence, but does not permit any conclusion concerning the pathogenicity of a strain. Indeed, their presence can be interpreted by precaution as enabling the bacterium to induce acute gastroenteritis if present in shellfish (Ceccarelli et al., 2015). But at present, there are still no markers of virulence validated for the pathogenic strains of non-O1/non-O139 V. cholerae. In view of the variety of the pathologies caused by non-O1/non-O139 V. cholerae, very numerous markers will probably be necessary to cover all the mechanisms of pathogenicity. These data would be essential to better manage the hazard for human health represented by the environmental isolates, in the context of the increase of cases of human vibriosis in Europe (Baker-Austin et al., 2016).

\section{Antimicrobial Susceptibility}

The existence of environmental strains of non-O1/non-O139 $V$. cholerae presenting acquired resistances was reported in the literature in cholera-free regions. Therefore, we undertook the study of the antibiotic resistance by choosing two compartments exposed to different pressures of antibiotics: wastewater coming from the sewage system of an urban area containing a hospital, and a field of wild shellfish located downstream in the estuary. This estuary is characterized by a low pressure of ground breeding and a few zones contaminated by farm effluent, but no fish farming.

In case of infection by non-O1/non-O139 V. cholerae, ciprofloxacin, or/and doxycycline or extended spectrum cephalosporin are the recommended treatments (Daniels and Shafaie, 2000). As all isolates tested here were susceptible to these antimicrobial agents, the loss of efficacy of such first line treatments was not to be feared.

Among the 99 environmental isolates tested, resistances were observed for only three antimicrobial agents: ampicillin, streptomycin and sulfonamides, and no significant difference was observed between wastewater $(n=48)$ or cockles $(n=51)$ origin These molecules are considered as "old antibiotics." In a similar context (cholera free area, temperate climate, and labeled use of antibiotics), recent studies on environmental isolates-collected in the Baltic Sea (Germany) ( $n=131$ isolates, between 2008 and 2014) (Bier et al., 2015) and in the Chesapeake Bay (USA) ( $n=307$ isolates, between 2009 and 2014) (Ceccarelli et al., 2015) were performed between 2008 and 2014. In our study, 9.0\% of the isolates were resistant to ampicillin, result in agreement with those of the two previous ones (16.3\% in the Chesapeake Bay and $7.6 \%$ in the Baltic Sea).

The resistance profiles observed in our strains collected in wastewater were very similar to those observed in $V$. cholerae isolated at the outlet of stabilization ponds in Marrakesh 10 years previously, except for streptomycin. The highest observed resistance rates were for streptomycin $(11.8 \%)$, and ampicillin (9.1\%) (Imziln and Hassani, 1994). All the 120 isolates of non-O1/non-O139 V. cholerae tested were susceptible to quinolones (nalidixic acid) and phenicols (chloramphenicol) and only one isolate was resistant to trimethoprim-sulfamethoxazole association. More recently, in Tanzania, all the strains of $V$. cholerae collected in wastewater were resistant to ampicillin 
and to tetracycline but quite susceptible to phenicol or quinolone (Hounmanou et al., 2016).

Wastewater is considered to be hot spots for the acquisition of resistance. Nevertheless, in our study, it is worth noting that there was not more resistance in wastewater than in shellfish. One of the explaining hypotheses could be the relatively low abundance of this bacterium in wastewater, compared to enteric species (like E. coli or intestinal Enterococci).

Six multidrug resistant strains were collected from cockles; they were resistant to ampicillin, streptomycin and sulfonamides (6\% of the isolates). The multi-resistant strains of environmental origin are rare in cholera-free areas. Bier et al. (2015) and Ceccarelli et al. (2015) thus detected no multi-resistant strains among 131 and 307 isolates respectively. But these authors did not test sulfonamides, which in our study accounted for the most frequent resistance.

All our isolates were susceptible to extended spectrum cephalosporins and none harbored the bla $a_{\mathrm{CTX}-\mathrm{M}}$ gene, one of the most important genes conferring this resistance to Enterobacteriaceae in France. These isolates were collected in 2000 and 2001; the dissemination of this gene in environmental strains appeared later and so its non-detection in our strains was not surprising. Even though 29.5\% (62/210) of non-O1/non-O139 V. cholerae isolated from tropical seafood in Cochin (India) in 2013 were resistant to cefpodoxime (Kumar and Lalitha, 2013), clearly, extended spectrum $\beta$-lactamase enzymes are uncommon in $V$. cholerae (Ceccarelli et al., 2016).

All isolates of $V$. cholerae collected in 2000-2001 in La Rance estuary were also susceptible to carbapenem, another critical antimicrobial agent. Since the beginning of the twenty-first century, environmental $V$. cholerae harboring carbapenemase genes have been reported several times in the literature, but this could be a bias linked to the interest focused on this antimicrobial resistance. Indeed, a gene conferring resistance to carbapenems has been detected in environmental isolates of non-O1/nonO139 V. cholerae, even in Europe. In France, one strain of $V$. cholerae isolated from cloacal swab samples from juvenile unfledged yellow-legged gulls (Larus michahellis) coharbored the bla $a_{\mathrm{VIM}-1}$ and bla $a_{\mathrm{VIM}-4}$ carbapenemase genes (Aberkane et al., 2015). Bier et al. (2015) identified a non-toxigenic V. cholerae harboring a carbapenemase gene that could not be identified by standard PCR typing. In Canada, a novel Amber class A carbapenemase was found in non-toxigenic $V$. cholerae strains isolated from shrimp intended for human consumption (Mangat et al., 2016). Given the potential ability of conjugative plasmids to transfer naturally between enterobacterial populations in the intestinal gut (Rashid and Rahman, 2015), the aquatic environment is now considered as an ideal setting for acquisition and dissemination of antibiotic resistance (Marti et al., 2014) and the horizontal transfer of ESBL/carbapenemase genes to $V$. cholerae cannot be ruled out.

On the basis of the distribution of a limited set of resistance genes (eight), our study shows that $V$. cholerae can constitute an environmental reservoir for these genes. However, none of the 99 isolates studied harbored integron. This result is in agreement with those of Bier et al. (2015) and Ceccarelli et al. (2015). As such mobile genetic elements play an important role in the acquisition and dissemination of antimicrobial resistance; this provides some confirmation for the conclusion drawn above from our susceptibility data, that, in our geographic context at least, nonO1/non-O139 V. cholerae seems not to have significant role in the dissemination of antibiotic resistance in the environment.

Nevertheless, integrons are not the only medium by which $V$. cholerae acquires antimicrobial resistance genes. Presence of integrative and conjugative element (ICE) has been regularly reported since the first description of the so-called SXT element in $V$. cholerae (Waldor et al., 1996) confering resistance to sulfonamides, trimethoprim, streptomycin and chloramphenicol. Further study should probably also target detection of specific markers to evaluate the presence of the SXT element in this nonO1/non-O139 V. cholerae collection. But, since multiple studies investigating either clinical or non-pathogenic collections of V. cholerae (Ceccarelli et al., 2006; Mala et al., 2016, 2017; Wang et al., 2016) had demonstrated that antimicrobial resistance genes carried by the SXT element are various, and $s u l 2, \operatorname{str} A$ and $\operatorname{str} B$ appeared to be the most commonly encountered resistance genes. We might hypothesize that the proportion of strains from our collection harboring the SXT element might be quite low.

\section{CONCLUSION}

In France, a cholera-free country, the presence of $V$. cholerae non-O1/non-O139 in treated wastewater of an urban area (11,000 inhabitants), and in cockles had never been investigated simultaneously in a same geographic area.

In similar epidemiological contexts, without any history of cholera cases but potentially different local antibiotic pressures, this study and two others (Bier et al., 2015; Ceccarelli et al., 2015) performed later on cast doubt on the capacity of $V$. cholerae non-O1/non-O139 to acquire resistance-associated genes and its potential role as indicator for the dissemination of antimicrobial resistance in the aquatic environment. However, $V$. cholerae presents the advantage of being a bacterium able to develop in the aquatic estuarine environment, unlike enteric bacteria which only survive for a limited time in receiving surface waters. Moreover, $V$. cholerae is known to be susceptible to carbapenems and to third generation cephalosporins, unlike Aeromonas spp., which is also more and more often proposed as candidate to be an indicator bacterium of antimicrobial resistance circulating in the aquatic environment (Usui et al., 2016; Varela et al., 2016; Baron et al., 2017). So, detection of $V$. cholerae harboring a mechanism of resistance to antibiotic critically important for Public health, such as carbapenems or third generation cephalosporins, could establish an alert on contaminated ecosystems.

Finally, those historical data would deserve now to be refreshed in order to determine if there has been a shift in the antimicrobial resistance genes harbored by the population of $V$. cholerae non-O1/non-O139 from La Rance Estuary over the past 20 years.

\section{AUTHOR CONTRIBUTIONS}

$\mathrm{SB}, \mathrm{EL}, \mathrm{EJ}, \mathrm{SC}$, and JL contributed to the design of the study. $\mathrm{SB}, \mathrm{EL}, \mathrm{SC}$, and JL produced data. All authors contributed to the 
analysis of the data, to the redaction and/or the edition of the article.

\section{ACKNOWLEDGMENTS}

The authors thank Roland Fleury (EHESP-LERES, Rennes) for efficient logistic support. The authors are grateful to Dr. MarieLaure Quilici, Centre National de Réference des Vibrions et du Choléra (CNRVC), Institut Pasteur, Paris, for providing reference strains. For their help and knowledge of the sampling sites, the authors are grateful to Dr. François Lang and Patrick Le Mao.

\section{REFERENCES}

Aberkane, S., Compain, F., Barraud, O., Ouédraogo, A.-S., Bouzinbi, N., Vittecoq, M., et al. (2015). Non-O1/Non-O139 Vibrio cholerae avian isolate from france cocarrying the blaVIM-1 and blaVIM-4 genes. Antimicrobial Agents Chemother. 59, 6594-6596. doi: 10.1128/AAC.00400-15

Alam, M., Miyoshi, S., Sonoda, Y., Chowdhury, M. A. R., Tomochika, K., and Shinoda, S. (1997). Role of a protease in the adherence and enterotoxicity of Vibrio mimicus. World J. Microbiol. Biotechnol. 13, 37-41. doi: 10.1007/BF02770805

Andersson, Y., and Ekdahl, K. (2006). Wound infections due to Vibrio cholerae in Sweden after swimming in the Baltic Sea, summer 2006. Electronic 11, 1560-7917.

Baker-Austin, C., Trinanes, J. A., Salmenlinna, S., Löfdahl, M., Siitonen, A., Taylor, N. G. H., et al. (2016). Heat wave-associated vibriosis, Sweden and Finland, (2014). Emerging Infect. Dis. 22, 1216-1220. doi: 10.3201/eid2207. 151996

Baker-Austin, C., Trinanes, J., Gonzalez-Escalona, N., and MartinezUrtaza, J. (2017). Non-cholera vibrios: the microbial barometer of climate change. Trends Microbiol. 25, 76-84. doi: 10.1016/j.tim.2016. 09.008

Baquero, F., Martínez, J. L., and Cantón, R. (2008). Antibiotics and antibiotic resistance in water environments. Curr. Opin. Biotechnol. 19, 260-265. doi: 10.1016/j.copbio.2008.05.006

Baron, S., Chevalier, S., and Lesne, J. (2007). Vibrio cholerae in the environment: a simple method for reliable identification of the species. J. Health Popul. Nutr. $25,312-318$

Baron, S., Granier, S. A., Larvor, E., Jouy, E., Cineux, M., Wilhelm, A., et al. (2017). Aeromonas diversity and antimicrobial susceptibility in freshwater-an attempt to set generic epidemiological cut-off values. Front. Microbiol. 8:503. doi: $10.3389 /$ fmicb.2017.00503

Baron, S., Lesne, J., Jouy, E., Larvor, E., Kempf, I., Boncy, J., et al. (2016). Antimicrobial susceptibility of autochthonous aquatic Vibrio cholerae in Haiti. Front. Microbiol. 7:1671. doi: 10.3389/fmicb.2016.01671

Barraud, O., Baclet, M. C., Denis, F., and Ploy, M. C. (2010). Quantitative multiplex real-time PCR for detecting class 1,2 and 3 integrons. J. Antimicrob. Chemother. 65, 1642-1645. doi: 10.1093/jac/ dkq167

Barrett, T. J., and Blake, P. A. (1981). Epidemiological usefulness of changes in hemolytic activity of Vibrio cholerae biotype El Tor during the seventh pandemic. J. Clin. Microbiol. 13, 126-129.

Beliaeff, B., and Mary, J.-Y. (1993). The "most probable number" estimate and its confidence limits. Water Res. 27, 799-805. doi: 10.1016/0043-1354(93)90 $143-6$

Bier, N., Schwartz, K., Guerra, B., and Strauch, E. (2015). Survey on antimicrobial resistance patterns in Vibrio vulnificus and Vibrio cholerae non-O1/non-O139 in Germany reveals carbapenemase-producing Vibrio cholerae in coastal waters. Front. Microbiol. 6:1179. doi: 10.3389/fmicb. 2015.01179

Bouki, C., Venieri, D., and Diamadopoulos, E. (2013). Detection and fate of antibiotic resistant bacteria in wastewater treatment plants: a review. Ecotoxicol. Environ. Saf. 91, 1-9. doi: 10.1016/j.ecoenv.2013.01.016
Olivier Barraud (UMR Inserm 1092, Limoges University, CHU of Limoges) provided the control strains and advices on PCR to detect integron. SB was supported by a doctoral fellowship (20002002) from Electricité de France, Service des Etudes Médicales, Paris, in EHESP-LERES, Rennes.

\section{SUPPLEMENTARY MATERIAL}

The Supplementary Material for this article can be found online at: http://journal.frontiersin.org/article/10.3389/fmicb. 2017.01637/full\#supplementary-material

Cantet, F., Hervio-Heath, D., Caro, A., Le Mennec, C., Monteil, C., Quemere, C., et al. (2013). Quantification of Vibrio parahaemolyticus, Vibrio vulnificus and Vibrio cholerae in French Mediterranean coastal lagoons. Res. Microbiol. 164, 867-874. doi: 10.1016/j.resmic.2013.06.005

Cantón, R., and Coque, T. M. (2006). The CTX-M $\beta$-lactamase pandemic. Curr. Opin. Microbiol. 9, 466-475. doi: 10.1016/j.mib.2006.08.011

Carraro, N., Rivard, N., Ceccarelli, D., Colwell, R. R., and Burrus, V. (2016). IncA/C conjugative plasmids mobilize a new family of multidrug resistance Islands in clinical Vibrio cholerae Non-O1/Non-O139 isolates from Haiti. MBio 7:4. doi: $10.1128 / \mathrm{mBio} .00509-16$

Ceccarelli, D., Alam, M., Huq, A., and Colwell, R. R. (2016). Reduced susceptibility to extended-spectrum B-lactams in V. cholerae isolated in Bangladesh. Front. Public Health 4:231. doi: 10.3389/fpubh.2016.00231

Ceccarelli, D., Bani, S., Cappuccinelli, P., and Colombo, M. M. (2006). Prevalence of aadA1 and dfrA15 class 1 integron cassettes and SXT circulation in Vibrio cholerae O1 isolates from Africa. J. Antimicrobial Chemother. 58, 1095-1097. doi: $10.1093 / \mathrm{jac} / \mathrm{dk} 1352$

Ceccarelli, D., Chen, A., Hasan, N. A., Rashed, S. M., Huq, A., and Colwell, R. R. (2015). Vibrio cholerae non-O1/non-O139 carrying multiple virulence factors and V. cholerae $\mathrm{O} 1$ in the Chesapeake Bay, Maryland. Appl. Environ. Microbiol. 81, 1909-1918. doi: 10.1128/AEM.03540-14

CLSI (2010). Performance Standards for Antimicrobial Suceptibility Testing. 25th Edn. CLSI SupplementM100S. Wayne, PA: Clinical and Laboratory Standards Institute.

CLSI (2015). Methods for Antimicrobial Dilution and Disk Susceptibility Testing of Infrequently Isolated or Fastidious Bacteria; Approved Guideline-3rd Edn. Wayne, PA: Clinical and Laboratory Standards Institute.

CLSI (2016). Performance Standards for Antimicrobial Suceptibility Testing. 26th Edn. CLSI SupplementM100S. Wayne, PA: Clinical and Laboratory Standards Institute.

Collin, B., and Rehnstam-Holm, A. S. (2011). Occurrence and potential pathogenesis of Vibrio cholerae, Vibrio parahaemolyticus and Vibrio vulnificus on the South Coast of Sweden. FEMS Microbiol. Ecol. 78, 306-313. doi: 10.1111/j.1574-6941.2011.01157.x

Coppo, A., Colombo, M., Pazzani, C., Bruni, R., Mohamud, K. A., Omar, K. H., et al. (1995). Vibrio cholerae in the horn of Africa: epidemiology, plasmids, tetracycline resistance gene amplification, and comparison between $\mathrm{O} 1$ and non-O1 strains. Am. J. Trop. Med. Hyg. 53, 351-359. doi: 10.4269/ajtmh.1995.53.351

Dalsgaard, A., Forslund, A., Hesselbjerg, A., and Bruun, B. (2000). Clinical manifestations and characterization of extra-intestinal Vibrio cholerae non01, non-0139 infections in Denmark. Clini. Microbiol. Infect. 6, 625-627. doi: 10.1046/j.1469-0691.2000.00174.x

Daniels, N. A., and Shafaie, A. (2000). A review of pathogenic Vibrio infections for clinicians. Infect. Med. 17, 665-685.

Di Cesare, A., Luna, G. M., Vignaroli, C., Pasquaroli, S., Tota, S., Paroncini, P., et al. (2013). Aquaculture can promote the presence and spread of antibiotic-resistant enterococci in marine sediments. PLOS ONE 8:e62838. doi: 10.1371/journal.pone.0062838

Fields, P. I., Popovic, T., Wachsmuth, K., and Olsvik, O. (1992). Use of polymerase chain reaction for detection of toxigenic Vibrio cholerae O1 strains from the latin American cholera epidemic. J. Clin. Microbiol. 30. 
Gatti, M., Stampi, S., Donati, M., De Luca, G., Aschbacher, R., and Zanetti, F. (1997). Characteristics of Non-o1 Vibrio cholerae isolated from the effluents of a treatment plant. New Microbiol. 20, 311-318.

Geneste, C., Dab, W., Cabanes, P. A., Vaillant, V., Quilici, M. L., and Fournier, J. M. (2000). Non-choleric vibriosis in France: cases identified between 1995 and 1998 by the national reference center. Feuill. Biol. 41, 73-75.

Hervio-Heath, D., Colwell, R. R., Derrien, A., Robert-Pillot, A., Fournier, J. M., and Pommepuy, M. (2002). Occurrence of pathogenic vibrios in coastal areas of France. J. Appl. Microbiol. 92, 1123-1135. doi: 10.1046/j.1365-2672.2002.01663.x

Hirk, S., Huhulescu, S., Allerberger, F., Lepuschitz, S., Rehak, S., Weil, S., et al. (2016). Necrotizing fasciitis due to Vibrio cholerae non-O1/non-O139 after exposure to Austrian bathing sites. Wien. Klin. Wochenschr. 128, 141-145. doi: 10.1007/s00508-0150944-y

Hochhut, B., Lotfi, Y., Mazel, D., Faruque, S. M., Woodgate, R., and Waldor, M. K. (2001). Molecular analysis of antibiotic resistance gene clusters in Vibrio cholerae $\mathrm{O} 139$ and $\mathrm{O} 1$ SXT constins. Antimicrobial Agents Chemother. 45, 2991-3000. doi: 10.1128/AAC.45.11.29913000.2001

Hombach, M., Courvalin, P., and Böttger, E. C. (2014). Validation of antibiotic susceptibility testing guidelines in a routine clinical microbiology laboratory exemplifies general key challenges in setting clinical breakpoints. Antimicrobial Agents Chemother. 58, 3921-3926. doi: 10.1128/AAC.02489-13

Hoshino, K., Yamasaki, S., Mukhopadhyay, A. K., Chakraborty, S., Basu, A., Bhattacharya, S. K., et al. (1998). Development and evaluation of a multiplex PCR assay for rapid detection of toxigenic Vibrio cholerae O1 and O139. FEMS Immunol. Med. Microbiol. 20, 201-207. doi: 10.1111/j.1574-695X.1998.tb01128.x

Hounmanou, Y. M. G., Mdegela, R. H., Dougnon, T. V., Mhongole, O. J., Mayila, E. S., Malakalinga, J., et al. (2016). Toxigenic Vibrio cholerae O1 in vegetables and fish raised in wastewater irrigated fields and stabilization ponds during a non-cholera outbreak period in Morogoro, Tanzania: an environmental health study. BMC Res. Notes 9:466. doi: 10.1186/s13104-0162283-0

Huehn, S., Eichhorn, C., Urmersbach, S., Breidenbach, J., Bechlars, S., Bier, N., et al. (2014). Pathogenic vibrios in environmental, seafood and clinical sources in Germany. Int J Med Microbiol. 304, 843-850. doi: 10.1016/j.ijmm.2014. 07.010

Imziln, B., and Hassani, L. (1994). Antimicrobial susceptibility of non-O1 Vibrio cholerae isolated from wastewater stabilization ponds in Marrakesh, Morocco. World J. Microbiol. Biotechnol. 10, 230-231. doi: 10.1007/BF00360895

Jones, J. L., Lüdeke, C. H. M., Bowers, J. C., DeRosia-Banick, K., Carey, D. H., and Hastback, W. (2014). Abundance of Vibrio cholerae, V. vulnificus, and V. parahaemolyticus in oysters (Crassostrea virginica) and clams (Mercenaria mercenaria) from long Island sound. Appl. Environ. Microbiol. 80, 7667-7672. doi: 10.1128/AEM.02820-14

Kumar, R., and Lalitha, K. V. (2013). Prevalence and molecular characterization of Vibrio cholerae O1, non-o1 and non-o139 in tropical seafood in Cochin, India. Foodborne Pathog. Dis. 10, 278-283. doi: 10.1089/fpd.2012.1310

Lesne, J., Baleux, B., Boussaid, A., and Hassani, L. (1991). Dynamics of non01 Vibrio cholerae in experimental sewage stabilization ponds under arid Mediterranean climate. Water Sci. Technol. 24, 387-390.

Mala, W., Faksri, K., Samerpitak, K., Yordpratum, U., Kaewkes, W., Tattawasart, U., et al. (2017). Antimicrobial resistance and genetic diversity of the SXT element in Vibrio cholerae from clinical and environmental water samples in northeastern Thailand. Infect. Genet. Evol. 52, 89-95. doi: 10.1016/j.meegid.2017.04.013

Mala, W., Kaewkes, W., Tattawasart, U., Wongwajana, S., Faksr, K., and Chomvarin, C. (2016). Sxt element, class 1 integron and multidrug-resistance genes of Vibrio cholerae isolated from clinical and environmental sources in Northeast Thailand. Southeast Asian J. Trop. Med. Public Health 47, 957-966.

Mangat, C. S., Boyd, D., Janecko, N., Martz, S. L., Desruisseau, A., Carpenter, M., et al. (2016). Characterization of VCC-1, a novel ambler class a carbapenemase from vibrio cholerae isolated from imported retail shrimp sold in Canada. Antimicrobial Agents Chemother. 60, 1819-1825. doi: 10.1128/AAC.028 $12-15$
Marti, E., Variatza, E., and Balcazar, J. L. (2014). The role of aquatic ecosystems as reservoirs of antibiotic resistance. Trends Microbiol. 22, 36-41. doi: 10.1016/j.tim.2013.11.001

Matté, G. R., Matté, M. H., Sato, M. I. Z., Sanchez, P. S., Rivera, I. G., and Martins, M. T. (1994). Potentially pathogenic vibrios associated with mussels from a tropical region on the Atlantic coast of Brazil. J. Appl. Bacteriol. 77, 281-287. doi: 10.1111/j.1365-2672.1994.tb03075.x

Mezrioui, N., and Oufdou, K. (1996). Abundance and antibiotic resistance of nonO1 Vibrio cholerae strains in domestic wastewater before and after treatment in stabilization ponds in an arid region (Marrakesh, Morocco). FEMS Microbiol. Ecol. 21, 277-284. doi: 10.1111/j.1574-6941.1996.tb00124.x

Morris, J. G. Jr. (1990). Non-O group 1 Vibrio cholerae: a look at the epidemiology of an occasional pathogen. Epidemiol. Rev. 12, 179-191. doi: 10.1093/oxfordjournals.epirev.a036052

Muic, V. (1990). Rapid quantitative test for Vibrio cholerae in sewage water based on prolongated incubation at an elevated temperature. Period. Biol. 92, 285-288.

Nandi, B., Nandy, R. K., Mukhopadhyay, S., Nair, G. B., Shimada, T., and Ghose, A. C. (2000). Rapid method for species-specific identification of Vibrio cholerae using primers targeted to the gene of outer membrane protein OmpW. J. Clin. Microbiol. 38, 4145-4151.

Ninin, E., Caroff, N., El Kouri, D., Espaze, E., Richet, H., Quilici, M. L., et al. (2000). Nontoxigenic Vibrio cholerae O1 bacteremia: case report and review. Eur. J. Clin. Microbiol. Infect. Dis. 19, 489-491. doi: 10.1007/s100960 000296

Okoh, A. I., Sibanda, T., Nongogo, V., Adefisoye, M., Olayemi, O. O., and Nontongana, N. (2015). Prevalence and characterisation of non-cholerae Vibrio spp. in final effluents of wastewater treatment facilities in two districts of the eastern cape province of South Africa: implications for public health. Environ. Sci. Pollut. Res. Int. 22, 2008-2017. doi: 10.1007/s11356-014-3461-z

Ottaviani, D., Leoni, F., Rocchegiani, E., Canonico, C., Masini, L., Pianetti, A., et al. (2011). Unusual case of necrotizing fasciitis caused by Vibrio cholerae O137. J. Clin. Microbiol. 49, 757-759. doi: 10.1128/JCM.02257-10

Ottaviani, D., Leoni, F., Rocchegiani, E., Santarelli, S., Masini, L., Di Trani, V., et al. (2009). Prevalence and virulence properties of non-O1 non-O139 Vibrio cholerae strains from seafood and clinical samples collected in Italy. Int. J. Food Microbiol. 132, 47-53. doi: 10.1016/j.ijfoodmicro.2009.03.014

Passalacqua, P. L., Zavatta, E., Bignami, G., Serraino, A., and Serratore, P. (2016). Occurrence of Vibrio parahaemolyticus, Vibrio cholerae and Vibrio vulnificus in the clam ruditapes philippinarum (Adams \& Reeve, 1850) from Emilia Romagna and Sardinia, Italy. Ital. J. Food Saf. 5, 41-46. doi: 10.4081/ijfs.2016.5709

Pei, R., Kim, S. C., Carlson, K. H., and Pruden, A. (2006). Effect of river landscape on the sediment concentrations of antibiotics and corresponding antibiotic resistance genes (ARG). Water Res. 40, 2427-2435. doi: 10.1016/j.watres.2006.04.017

Popowska, M., Rzeczycka, M., Miernik, A., Krawczyk-Balska, A., Walsh, F., and Duffy, B. (2012). Influence of soil use on prevalence of tetracycline, streptomycin, and erythromycin resistance and associated resistance genes. Antimicrobial Agents Chemother. 56, 1434-1443. doi: 10.1128/AAC.05766-11

Rader, A. E., and Murphy, J. R. (1988). Nucleotide sequences and comparison of the hemolysin determinants of Vibrio cholerae El Tor RV79(Hly+) and RV79(Hly-) and classical 569B(Hly-). Infect. Immun. 56, 1414-1419.

Rashid, H., and Rahman, M. (2015). Possible transfer of plasmid mediated third generation cephalosporin resistance between Escherichia coli and Shigella sonnei in the human gut. Infect. Genet. Evol. 30, 15-18. doi: 10.1016/j.meegid.2014.11.023

Reidl, J., and Klose, K. E. (2002). Vibrio cholerae and cholera: out of the water and into the host. FEMS Microbiol. Rev. 26, 125-139. doi: 10.1111/j.1574-6976.2002.tb00605.x

Rhodes, J. B., Schweitzer, D., and Ogg, J. E. (1985). Isolation of non-01 Vibrio cholerae associated with enteric disease of herbivores in western Colorado. J. Clin. Microbiol. 22, 572-575.

Rivera, I. N. G., Chun, J., Huq, A., Sack, R. B., and Colwell, R. R. (2001). Genotypes associated with virulence in environmental isolates of Vibrio cholerae. Appl. Environ. Microbiol. 67, 2421-2429. doi: 10.1128/AEM.67.6.2421-2429.2001 
Rizzo, L., Manaia, C., Merlin, C., Schwartz, T., Dagot, C., Ploy, M. C., et al. (2013). Urban wastewater treatment plants as hotspots for antibiotic resistant bacteria and genes spread into the environment: a review. Sci. Total Environ. 447, 345-360. doi: 10.1016/j.scitotenv.2013.01.032

Tarantola, A., Ioos, S., Rotureau, B., Paquet, C., Quilici, M. L., and Fournier, J. M. (2007). Retrospective analysis of the cholera cases imported to France from 1973 to 2005. J. Travel Med. 14, 209-214. doi: 10.1111/j.1708-8305.2007. 00129.x

Usui, M., Tagaki, C., Fukuda, A., Okubo, T., Boonla, C., Suzuki, S., et al. (2016). Use of Aeromonas spp. as general indicators of antimicrobial susceptibility among bacteria in aquatic environments in Thailand. Front. Microbiol. 7:710. doi: $10.3389 /$ fmicb. 2016.00710

Varela, A. R., Nunes, O. C., and Manaia, C. M. (2016). Quinolone resistant Aeromonas spp. as carriers and potential tracers of acquired antibiotic resistance in hospital and municipal wastewater. Sci. Total Environ. 542, 665-671. doi: 10.1016/j.scitotenv.2015. 10.124

Waldor, M. K., Tschape, H., and Mekalanos, J. J. (1996). A new type of conjugative transposon encodes resistance to sulfamethoxazole, trimethoprim, and streptomycin in Vibrio cholerae O139. J. Bacteriol. 178, 4157-4165. doi: $10.1128 /$ jb.178.14.4157-4165.1996
Wang, R., Yu, D., Yue, J., and Kan, B. (2016). Variations in SXT elements in epidemic Vibrio cholerae O1 El Tor strains in China. Scientific Reports 6. doi: $10.1038 /$ srep 22733

Wassenaar, T. M., and Gaastra, W. (2001). Bacterial virulence: can we draw the line? FEMS Microbiol. Lett. 201, 1-7. doi: 10.1111/j.1574-6968.2001.tb10724.x

Woodford, N., Fagan, E. J., and Ellington, M. J. (2006). Multiplex PCR for rapid detection of genes encoding CTX-M extended-spectrum $\beta$ lactamases. J. Antimicrob. Chemother. 57, 154-155. doi: 10.1093/jac/ dki412

Conflict of Interest Statement: The authors declare that the research was conducted in the absence of any commercial or financial relationships that could be construed as a potential conflict of interest.

Copyright (C) 2017 Baron, Larvor, Chevalier, Jouy, Kempf, Granier and Lesne. This is an open-access article distributed under the terms of the Creative Commons Attribution License (CC BY). The use, distribution or reproduction in other forums is permitted, provided the original author(s) or licensor are credited and that the original publication in this journal is cited, in accordance with accepted academic practice. No use, distribution or reproduction is permitted which does not comply with these terms. 